\title{
A Survey of Human-Computer Interaction Design in Science Fiction Movies
}

\author{
Michael Schmitz \\ DFKI GmbH \\ michael.schmitz@dfki.de
}

\author{
Christoph Endres \\ DFKI GmbH \\ christoph.endres@dfki.de
}

\author{
Andreas Butz \\ University of Munich, Germany \\ butz@ifi.Imu.de
}

\begin{abstract}
Science Fiction movies have always been a medium for speculation about the future of technology. The most visible part of technology often is its interaction design, which therefore appears prominently in these movies. This paper presents a survey of human-computer interaction designs in SciFi movies during the past decades and it relates the techniques shown there to existing technologies and prototypes in research. Different types of interaction are categorized according to their application domain in real life and compared to current research in human-computer interaction.
\end{abstract}

\section{Categories and Subject Descriptors}

H.5.2 [User Interfaces]; I.3.6 [Methodology and Techniques]: Interaction techniques; K.4.m [Computers and Society]: Miscellaneous

\section{General Terms}

Science Fiction Movies, Interaction Design

\section{INTRODUCTION}

The motion picture industry is a major entertainment sector with a considerable impact on the general public mindset throughout all social classes. In return some producers or directors attempt to catch the spirit of the time, trying to pick up existing or emerging trends, which leads to interesting interactions between fictional worlds and the real one. Particularly science-fiction movies - due to their inherent theme - are set in a world with advanced, fictional technology that is normally set in the future. Most of these movies expose their own unique vision of the future, with new technologies commonly being the most noticeable change in these hypothetical worlds. Besides visions regarding all kinds of technologic and scientific areas, human-computer interfaces are an important recurring component as they visualize otherwise abstract and possibly invisible technologies.

Permission to make digital or hard copies of all or part of this work for personal or classroom use is granted without fee provided that copies are not made or distributed for profit or commercial advantage and that copies bear this notice and the full citation on the first page. To copy otherwise, or republish, to post on servers or to redistribute to lists, requires prior specific permission and/or a fee.

The Second International Conference on Intelligent Technologies for Interactive Entertainment (ICST INTETAIN '08). January 8-10, 2008, Cancun, Mexico. Copyright 2008 ICST. ISBN 978-963-9799-13-4.

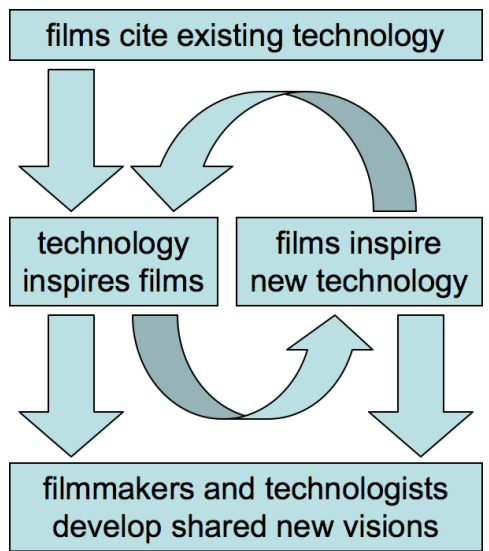

Figure 1: Different ways in which filmmakers and researchers collaborate

In this paper we provide a survey of prominent science fiction films and analyse them regarding their references in real-life human-computer interaction (HCI) research, outlining similarities to ongoing research. In order to be able to draw comparisons to reality, it is often necessary to view the ideas and visions of a movie on a relatively abstract level. We observed an interesting development in the history of science-ficion movies, beginning with films unrelated to technological tendencies. This phase was followed by movie makers taking current trends into account and by ideas of movies inspiring researchers, until finally movie makers and HCI researchers are found to work together to create artificial yet authentic worlds (see fig.1).

At first some key factors which determine or influence the design of HCI in movies will be discussed. Starting from this viewpoint, numerous examples from selected movies will be discussed in mostly chronological order. We do not claim to provide a complete overview of all existing movies, but the presented selection allows a representative inspection of the movie scene and nicely shows the evolution as stated above. We will start with a review of movies that do not show any concepts at all or merely adapt common everyday techniques of that time. The second and main part introduces visionary interaction design which attempts to catch up with contemporary technologies, divided into different fields of HCI, followed by movie elements that might have inspired research. We close our survey with a brief look at some satiric movie scenes and a concluding discussion. 


\section{INFLUENCING FACTORS FOR INTER- ACTION DESIGN IN MOVIES}

Before discussing selected cut-outs, we will briefly examine the key factors that contribute to the resulting interaction techniques: Special effects (FX) technologies, budget and importance of technology in the movie. We will then keep these in mind for the following evaluation, in order to have a better understanding of the historical context of the respective movies. Presumably, the most important aspect is the availability of special FX technologies at all, since this is limiting the subset of the directors' imaginations which can actually be satisfactorily implemented. Some movies that we examined were made at a time when digital editing was not yet existent, whereas more recent motion pictures (e.g. STAR WARS: EPISODE $\mathrm{II}^{1}$ ) don't even contain a single scene without computerized backgrounds or animations.

While the availability of Special FX at a given time is certainly a basic requirement, often the general budget determines the commercial success of a movie. Average budgets in the movie industry have increased substantially during the past two decades, such that more realistic versions of future technology became feasible.

Contemporary IT research and products also have an impact on movies, since they provide the directors' background and the foundation for their ideas. Given the fact, that technical realisations of technologies in movies do not have to be explained or justified, the directors benefit from an almost unlimited degree of freedom, making the resulting vision a very personal product.

We also have to consider the importance of the interaction technique or the device itself for the movie as a whole. The technology could be totally unimportant or play an important role for the plot (so called plot device), requiring more attention by the makers. But more often, technology is found inbetween and has to support the overall authenticity of the vision of a future world.

Finally, It can be observed that there are two kinds of approaches to staging futuristic human-computer interactions: Some have a clean, idealised design that appears very smooth and error free whereas others introduce flaws and drawbacks to add realism.

\section{MOVIES ADOPTING CURRENT HCI}

In this section we will review movies which lack any concept of HCI whatsoever or which just adapted common technology of their time without adding new ideas beyond them. Even in these adaptations, however, several levels of creativity can be found. In the very first science fiction movies, there was obviously little or no use of contemporary computerlike technology. The timeline of science fiction movies starts in 1902 with the 14 minute silent film LE VOYAGE DANS LA LUNE ${ }^{2}$ (A TRIP TO THE MOON) by the french director Georges Méliès. It was very popular at that time. The computer, however, was not invented until Konrad Zuse finished his Z1 in 1938 and was not known to the general public until much later. At this point, computer technology was basically used in movies without much vision beyond a general

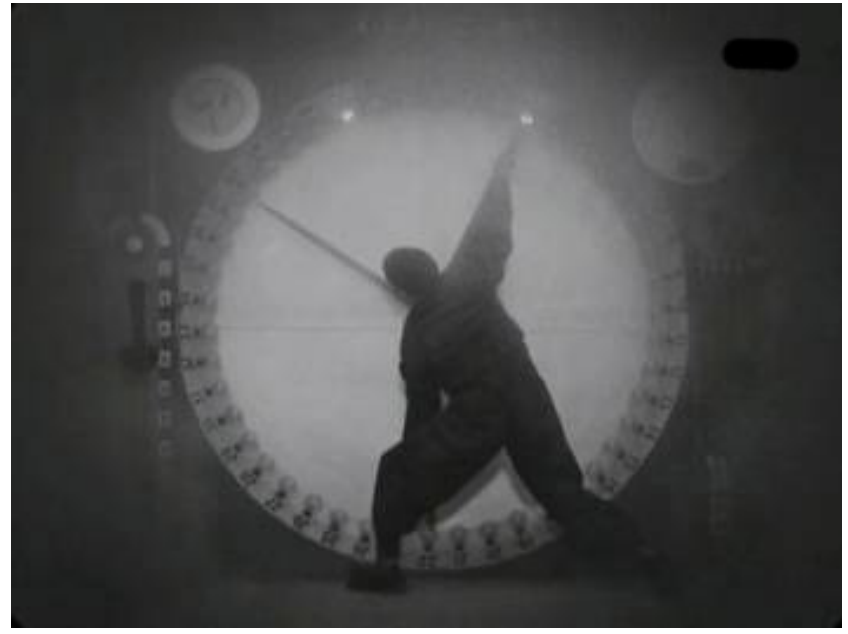

Figure 2: Worker operating a machine in Metropolis

scaling of the existing capabilities, such as storage size or processing speed. Later on, roughly in the 1980ies, there are some examples of advanced technologies in movies but with no general change in terms of interaction.

\subsection{Pre-Computer Interaction}

One of the oldest science fiction films to show some sort of human-machine interaction is the German movie METROPOLIS $^{3}$ by Fritz Lang from 1927. Its rather untypical dystopian elements and visual design became a huge influence in art and popular culture, ranging from the paintings of Konrad Zuse to usage and quotes in pop music and music videos. The topic of the film is a large automated industrial city with a society divided into two classes, the thinkers and the workers. The interaction with machines - which are inspired by clockwork-based mechanics, not computer technology - is depicted by machines enslaving and commanding the workers underground. In one of the key scenes, we see a worker, or more accurately a slave, adjusting huge levers according to visual signals given by the machine (see fig.2). This contorted perspective - the human is working for the machine, not vice versa - indicates how vague the vision of future technology and its applications was at that time and expresses a concern that technology might be used to support the powerful.

\subsection{Simple technology adaptation}

RAumpatrouille Orion ${ }^{4}$ (SPACE PATROL) was a German seven episode TV series from 1966 which premiered just a few days before the start of the original Star Trek series in the United States. It was very popular back then (audience rating of 41\%), and continues to be. A feature length edit of the seven episodes with some new footage was at the movie theatres in 2003.

Budget and time restrictions (the complete series was filmed in only six weeks) however led to a lot of improvisation in set design. Among the ship's controls are fauctes, pencil sharpeners and other household items, which are integrated into the control panel. The most remembered feature, however, is a clearly recognizable flat iron, which is used to steer the ship (see fig.3). 


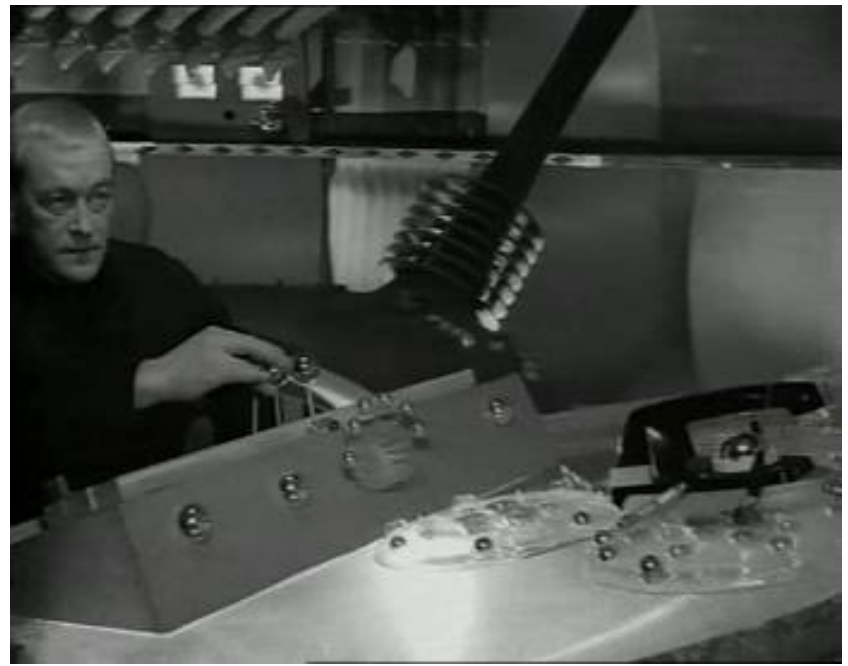

Figure 3: Spaceship controls in Raumpatrouille Orion

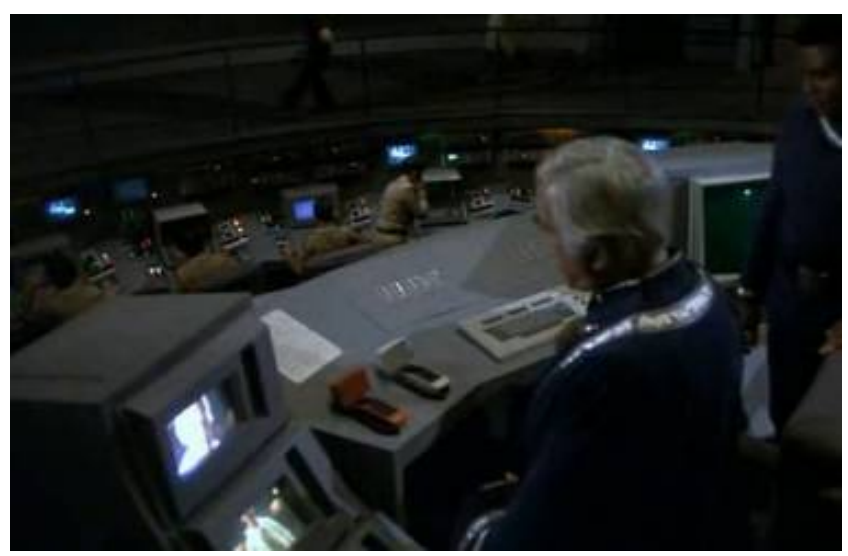

Figure 4: Control panels in Battlestar Galactica

Another scene shows an engineer programming the main computer: He is holding a punch card in one hand and typing on a small keyboard with the other hand. Punch-cards were still used at that time for computer in- and output, which explains the appearance of it, but using them by reading and typing in what is encoded or 'written' on them is clearly a step back from the original intended usage.

More than a decade later, BAttlestar GalacticA ${ }^{5}$ (1978) still shows some amazingly simple adaptation of state-ofthe-art technology and computer interaction. The "colonial vipers" in this film, for instance, are controlled by a lever that bears a striking resemblance with joysticks and they are even controlled in the same way: tilting the controller sideways changes direction, moving it backward and forward controls speed and three buttons are intuitively labeled 'fire', 'turbo' and 'im'. Also, the interior of the main ship's bridge appears very similar in design and usage to real life technical control centers of at that time, for instance NASAs mission control center. We see TV screens, phone receivers with cables and keyboards built-in to the desks (see fig.4).

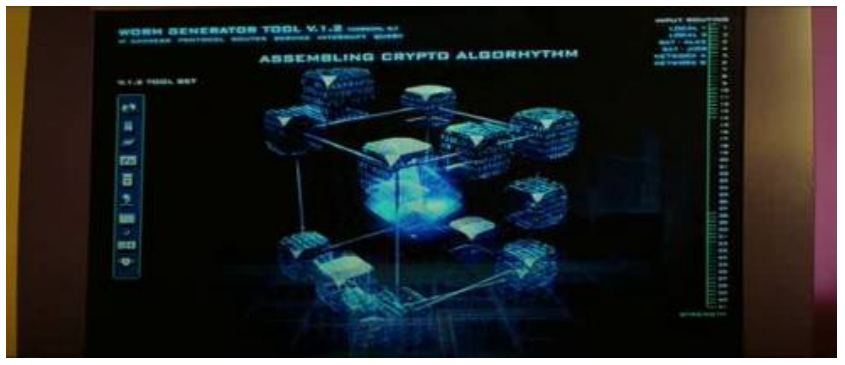

Figure 5: Programming in Password Swordfish

A more recent example is PAssword SwORdFish ${ }^{6}$ from 2001, where a professional hacker is hired by a terrorist organisation to do some jobs for them. A programming environment was prepared, which consists of 7 flatscreen monitors of common size put together and probably supposed to be used as an enhanced display. The actual programming of the virus takes place with a graphical 3D interface (see fig.5).

As the whole movie primarily intends to achieve a fancy and cool look, there is no further information about the underlying concept of this user interface.

\subsection{Advanced technology with well-known in- teraction}

Some movies show well-known types of human-computer interaction with technology far advanced over the actual technological possibilities of that time. Examples are speech interfaces, fingerprint recognition and virtual reality type technologies.

A typical VR setup with a head-mounted display and data gloves is used in one scene of JohnNy MnEmonic ${ }^{7}$, a socalled "cyberpunk" movie with Keanu Reeves, playing an agent, who is using this interface to retrieve information from the internet by browsing through an abstract 3D world, manipulating various objects to access sites.

Most of the interactions are not explained and obviously don't make much sense in this context, but one metaphor looks interesting: Every new session is started by a gesture that looks like opening a book.

The most popular example is probably the main computer of the USS Enterprise, the spaceship of STAR TREK - ThE Next Generation ${ }^{8}$ (STTNG). The computer handles all kinds of requests and replies to all commands with an acoustic signal, to indicate the receipt of the request.

Speech recognition and synthesis appears very frequently, especially for robots - in recent movies as well as in old ones. The advantage of speech is its intuitiveness for control commands and to perceive information. Besides, it is very easy to realize this in a movie: no special effects are needed, just actors imitating the dialog with the computer. In most movies, the speech interface is conversational and intuitive, the particular difficulties of speech recognition and language understanding are never considered. The first conversational speech interface was depicted in Colossus: The Forbin PROJECT $^{9}$ in 1970. 


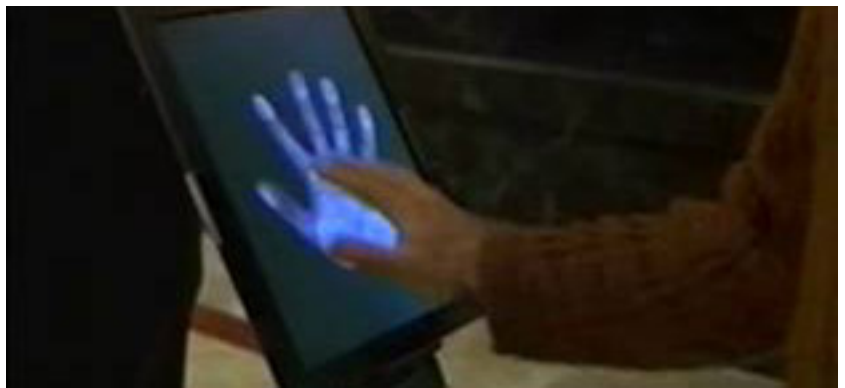

Figure 6: Palm-print recognition in The Bourne Identity

Automated palm-print identification systems are already commercially available from several companies, and they are most often used for security applications. Such a system is shown in The Bourne IDENTITY ${ }^{10}$, where the main character has to access his locker in a Swiss bank (see fig.6).

In reality, the hand is scanned by placing it on a high resolution scanning device, but in this film, a common (possibly touch-) screen was used to obtain the palm-print, giving an immediate visual response to the user. This scenario looks more sophisticated and high-tech with this extra feature, accepting the loss of realism, which is not too obvious at first sight. Nowadays, finger print sensors are very common in modern laptop computers, as a convenient alternative to authentication by password.

\section{MOVIES WITH UNREALIZED HCI VI- SIONS}

Beyond adopted technologies, there are movies, which have their own unique visions of human-computer interaction. Some of these visions were just never implemented, while others most probably never will be - from our current point of view. The movie clips of this chapter are categorized according to their area of real-life applications and research:

Invasive Neural Interfaces: Although the corresponding research field is more concerned with supporting disabled people than with HCI for a wide audience, we included this type of interaction, since it still represents interaction between humans and computers in a literal sense, and also because it seems popular in recent movies:

The first example is taken from Johnny Mnemonic ${ }^{7}$ : The specialty of the agent is to deliver sensitive data using his brain as a storage device. Film scenes show the transfer of data over a wire which is connected by plugging it into a socket under the actor's ear. For unknown reasons the actor also wears a head-mounted display during this procedure. In The MATRIX ${ }^{11}$, the same actor, Keanu Reeves, plays a role in which his brain is interfaced to a computer (One might speculate about reusing the sockets..). As with all other humans in the envisioned future of that movie, a computer controls his consciousness by accessing his brain physically through the back side of his head. The main characters here enter and leave the artificial world by (un-)plugging a connector into "sockets" of their brain.
In reality, in turn, non-invasive versions of neural interfaces are starting to produce useful results for a wider public, such as the Berlin Brain Computer Interface BBCI [1]. It is plausible that in the relatively near future basic interaction techniques can be executed by thought using these technologies.

Identification: Electronic identification of individuals is mostly introduced in a movie in order to be exploited later on in the plot. Identification techniques are, for example, used to track individuals during their everyday life, and in such cases the privacy / security issues are the main aspects the directors try to bring into their work:

People in the future presented in LOGAN's RuN ${ }^{12}$ live in a perfect, harmonic society, the only purpose of which is enjoyment. The drawback is, that people have to be killed at an age of 30, which happens during a ceremony everybody attends. To avoid panic or revolts among those who are supposed to die, everybody is told that they will be reborn instantly. Every child will get a diamond-like implant into its palm at the day of birth, which allows to track and identify the person and display their life-stage by its colour. Although RFID implants are nowadays feasible e.g. for storing or pointing at your medical record - they don't provide output capabilities or are used as a control and observation tool.

In GATTACA ${ }^{13}$ an aerospace academy uses DNA analysis to identify individuals; a drop of blood is taken by a machine and analyzed in realtime. The choice of this identification technique most probably originates from the main theme of the movie, which is the genetic determination of human beings. Individuals are defined by their genetic patterns, which can be chosen by the parents to alter one 's fate. DNA analysis and identification was invented in 1985 and became a tool in crime fighting. A database is already maintained in some countries [4] and assuming that the costs can be reduced and the procedure of analysis speeded up, this vision is not too far-fetched. But it is not necessary to take blood of the object, any part of the body would suffice any might be more convenient, for instance hairs or saliva.

ALIEN IV ${ }^{14}$ uses a identification technique that is not being researched and probably never will, because it is very doubtful if sufficient physiological data can be extracted from its medium: The breath ID. Apparently the odor of a person's breath is analyzed to grant or deny access to certain areas of the ship. This idea seems to be an attempt of the director to find a new and unique element for his movie.

An indepth view on biometrics in science fiction movies was given during the 23rd Chaos Communication Congress ${ }^{1}$.

Displays have the advantage for moviemakers that they are inherently visual, characters using them have to look at them, and hence the audience watching the movie will see them as well, whenever they are used. It is obviously much easier to visualize new ideas for display technologies than for a new generation of CPUs, for example.

\footnotetext{
${ }^{1}$ http://events.ccc.de/congress/2006/Fahrplan

/events/1600.en.html
} 


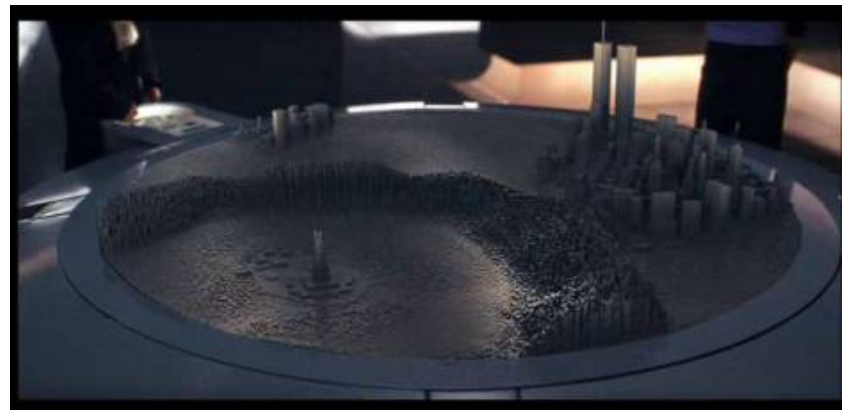

Figure 7: Physical Display in X-Men

A method to display 3 dimensional data is used in $\mathrm{X}-\mathrm{MeN}^{15}$, where a mission briefing is conducted with a physical display on a big table. The technology is not explained, but the surface seems to consist of small metallic cubes that are formed to the shape of the displayed objects by raising them to the appropriate level (see fig.7).

In research, a current approach to displaying 3-dimensional images physically is Table Top Spatially Augmented Reality, where physical structures are augmented by projections [10], but this concept is still far away from a dynamic physical display as seen in this example.

Holographic displays are very popular among directors and are used in movies quite frequently: In ForBIDDEN PLANET ${ }^{16}$ from 1956 the so-called thought analyzer, a device inherited from the planet's former inhabitants, displays a three dimensional image. Personal Computers were certainly not yet commonly known at that time, so not even a single $2 \mathrm{D}$ display appears in that movie, simple indicator lights were used for computer output - except for this device.

Other I/O technologies: The makers of the movie JoHnNy MNEMONIC $^{7}$ envisioned a gesture recognition for controlling the mimics of a computer animation. A green grid, which strongly reminds of the calibration image of a CRT projector, is projected onto the hand, indicating a visual recognition. As implemented in the movie it wouldn't be possible to determine the hand's movements using the alignment to the grid pattern, it would not even make much sense to do so in this context. But for the scene, it was necessary to show that the face is not the person itself, but just an animation that is controlled by someone else.

The concept of virtually overlaying everyday objects with functions is picked up by THE MATRIX ${ }^{11}$, too: When the main character Neo was offered two pills, he could decide to stay in the matrix or leave it. The feature of the world of MATRIX ${ }^{11}$, that people actually live in a virtual, computer generated world, has the interesting side effect that all actions in this world can be seen as manipulations of a computer system. This could actually be seen as the inversion of the ubiquitous computing paradigm, where the real world is overlaid with virtual functions. So both in the ubicomp world and in the matrix, people interact with the natural, physical environment surrounding them but, at least in their own perception, while they potentially trigger an invisible computersystem.
This means - in the context of the matrix as a computer program - that the pills represent a choice similar to buttons. The metaphor of swallowing a pill as a trigger automatically raises the user's attention to this choice due to the natural restraint of taking pills, which underlines the importance of the decision in this scene. More augmented everyday objects are landline and mobile phones. Stationary phones can represent exit and entry points to the matrix on the virtual side and are used by picking up the phone receiver or putting it down. Mobile phones are used for communication between people within the matrix and those outside. This approach has the advantage for the director, that he can visualize communication between the two 'worlds' clearly and unambiguously for the audience without further explanation.

\section{MOVIES ANTICIPATING OR INSPIRING FUTURE HCI CONCEPTS}

In some cases, visionary movies manage to show technology and HCI, which is actually realized in the real world at a later time. In most cases, it is not a trivial task to figure out whether the film maker's vision was accurate enough for a precise prediction, whether later developments were inspired by a movie, or whether some developments are just a logical consequence of previous developments, both in art and engineering.

In some cases though, it seems very obvious where an inspiration came from. It is probably not a coincidence that the first clam shell cell phone, produced by Motorola in the mid 90ies, was called StarTac and resembles the communicators in the original Star Trek series from the sixties. Also, to give an example outside the movie business, the name of Honda's famous robot Asimo is almost identical with the name of the science fiction writer Isaac Asimov who invented the word 'robotics'. Due to its enormous popularity, the STAR TREK ${ }^{17}$ franchise seems to play a special role in this context, and was supported by the tendency to reasonably explain at least some of the Star Trek technology. In some cases this worked relatively well, while there are other exanmples (e.g. Heisenberg compensator) which can only be considered a scientific joke or plot device.

Other popular series add less to the vision of HCI. The focus of STAR WARS ${ }^{18}$ for instance was always more on the ethical or spiritual side, concerned with the battle between good and evil, and less concerend with technological concepts or realism. The british television series SPACE 1999 on the other hand was always attempting to be scientifically correct in terms of how spaceships move etc., but did not add a lot of visionary concepts in the use of computers.

Another example is taken from Star Trek: The NeXt GENERATION $^{8}$ (STTNG), a TV series launched in 1987. In this series, you will notice 3 kinds of devices or displays of different size:

- The Tricorder, a small and handy device that looks very similar to a PDA, equipped with many sensors and used for outdoor analysis.

- A tablet used at the machine deck and sick bay: a very thin device, in the shape of a piece of paper 
- Wall screens almost everywhere on the ship, used to display data for multiple users.

These device categories were probably inspired by familiar classes of mundane artifacts, such as small note pads or address books, A4 or letter size paper, and blackboards or posters. One typical scene shows the usage of a tablet together with a wall screen at sick bay. The doctor seems to transfer data from the tablet PC that she is holding to the wall screen using a light pen. The reality is probably that she is holding a piece of plastic together with a small flashlight.

This choice also coincides with the device classes identified in early ubiquitous computing research, such as the ParcTab project at Xerox PARC [18], in which devices were also categorized into 3 classes: the so-called tabs, pads and boards. Tabs are very small and personal devices, which can be used for private tasks or provide context information about the user wearing them. Pads are envisioned as a conceptual mixture between a sheet of paper and a computer, lying around on tables and used spontaneously by any user. Boards are big screens on tables or at walls, which especially support collaborative work. The fact, that this project and the TV series started at the same time is quite interesting, and it is not clear if one has inspired the other or if the similarity is only a coincidence, since this classification of devices could be seen as relatively obvious and straightforward.

Total ReCALL ${ }^{19}$ introduces an ambient display embedded in a wall that can be used as a regular screen (in this case a $\mathrm{TV}$ ), when needed, or just display a picture of a scenery and merge with the users' environment whenever it is not in use. The display consists of 3 parts, and visually reminds of the DynaWall concept from the i-Land project at Fraunhofer IPSI[17] or the large display in Stanford's iRoom [5] (see fig. 8). The DynaWall provides an interaction space for CSCW, so the similarity between this project and the screens in the movie scene are merely of a visual kind, but striking nevertheless.

More motion tracking can be found in TOTAL RECALL ${ }^{19}$, when the female main character practices her tennis serve with a holographic projection explaining and demonstrating the correct movements. She tried to imitate the virtual trainer and visual and spoken feedback confirms matching movements. This idea wouldn't be difficult to realize, except that 3 dimensional images without head-mounted displays using air as the medium can't be built yet. The user's motions could be tracked efficiently, for instance with a camera or by embedding sensors into both wrist-belts that provide 6 degrees of freedom. The whole scene looks very similar to the way in which people play computer games nowadays on a Nintendo Wii console.

Holographic displays are generally very popular among directors and occur quite frequently: In FORBIDDEN PLANET ${ }^{16}$ from 1956 the so-called thought analyzer, a device inherited from the planet's former inhabitants, displays a threedimensional image. Personal Computers were certainly not yet commonly known at that time, so not even a single $2 \mathrm{D}$ display appears in that movie, and simple indicator lights were used for computer output - except for this device. A

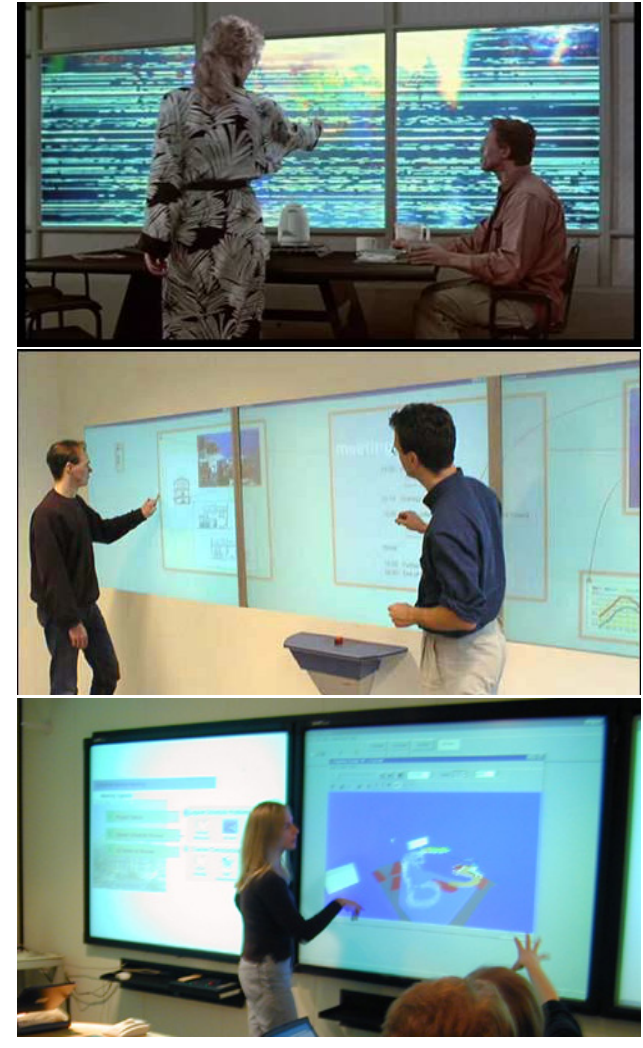

Figure 8: Top to Bottom: Scene from Total Recall, Dynawall, iRoom

classic example of a holographic display is the projection of princess Leia in the original STAR WARS ${ }^{18}$ movie. A visually very close implementation was demonstrated in the 2007 ACM Siggraph Emerging Technologies exhibition [6], where a $360^{\circ}$ lightfield display was shown. With this technology, it is indeed possible to display spatial output which can be observed from all directions, but currently only at great technological expense, and not in arbitrary free spaces, as in the movies. Also, The MATRIX ${ }^{11}$ contains an example of a holographic device, which is attached to the ship's controls and displays monochrome, but 3-dimensional images.

In the very first episode of $\mathrm{STTNG}^{8}$, the main computer's function as an indoor navigation system is introduced, leading Commander Riker to his colleague Data. The system assists him in a multi-modal fashion with a spoken way description and additional arrows on his way. Mobile and multi-modal navigation systems have been the subject of several research projects over the past decade.

The first time, artificial intelligence was shown in a movie, was the HAL9000 computer in Stanley Kubrick's classic 2001 - Space Odyssey ${ }^{20}$. This computer, which was in charge of a spaceship, was sent out for exploration purposes, until some of the crew members noticed its abnormal behavior. Two of them locked themselves in a small shuttle within the ship's bay, such that they were acoustically isolated and could discuss the situation, assumedly without HAL9000's knowledge. Tragically, they were not aware of the fact, that the computer still had visual contact, seeing 


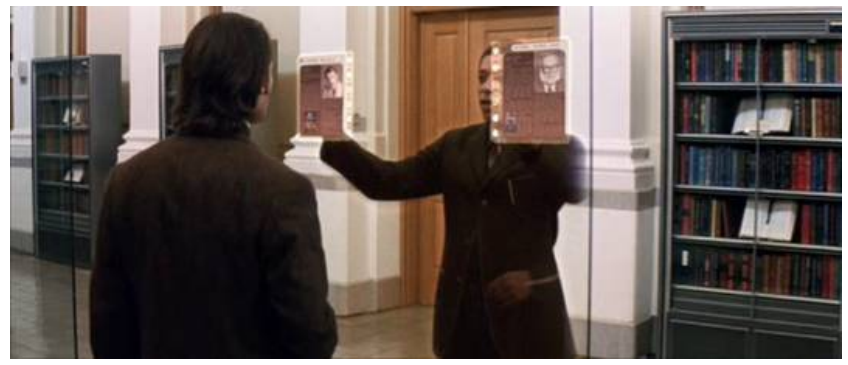

Figure 9: Avatar in Time Machine

their faces. By interpreting their lip movements it was able to understand their conversation, with the consequence that it started killing the crew one by one to prevent its own shutdown. Indeed, there is current research on automated lip reading, for example by the german deaf mute speech recognition expert Frank Hubner, which helped in dubbing some silent movies by Eva Braun in the 1940ies.

The idea of computers and machines being concious was also picked up by John Carpenter in his low-budget production DARK STAR ${ }^{21}$ and extended such that other parts of the ship also had their own identity. Here, interacting with them was more like interacting with human colleagues. A key scene of that movie shows the bomb on board of the ship, which was ordered to detonate after a specific time. Unfortunately a malfunction caused it to be stuck in its bay, but it refused to cancel the previous order to explode. One of the crew members tried to engage the bomb into a meta-physical dialogue to convince it not to follow these orders. After logically proving it's own existence ("I think therefore I am"), the bomb learns about phenomenology and the unreliabilty of any sensory input. The idea of associating personalities to speech interfaces of everyday objects is currently being explored $[13,14]$ with the objective of providing an intuitive interface to non-expert users to access complex computerized environments.

The last example in this section is an intelligent assistant who serves as a library guide, taken from the 2002 remake of Time Machine ${ }^{22}$. The main character travels into the 22nd century and encounters this avatar on his search for more information about time travelling. Personal guides for museums or exhibitions are not new and exist as prototypes and also as commercial solutions. They are mostly PDA-based and sometimes support kiosks - stationary machines with more resources from which the user can retrieve information of higher quality. The $\mathrm{PEACH}$ project [12] is one example for this work. Here it is also possible for the avatar to migrate from the PDA to a kiosk or vice versa [7]. In Time MACHinE ${ }^{22}$ multiple transparent, human-sized displays are installed everywhere in the library, such that the computer character (the intelligent assistant) can follow and assist the user everywhere in the building. The avatar displays different kinds of (2D) information on the screens and also interacts with the environment that is visible through the displays (see fig.9).

So, for the user in this case, the environment becomes an augmented reality, overlaid by the avatar's reactions, such as pointing to a book. The concept of a virtual avatar which is capable of performing deictic references to objects in the real world was discussed and realized in 2005 [8].

\section{COLLABORATION BETWEEN MOVIE AND HCI VISIONARIES}

The evolution of HCI in movies eventually led to Steven Spielberg's MinORITY REPORT ${ }^{23}$, to our knowledge the first film project, which involved HCI scientists as much as possible, in order to construct authentic visions of future computer usage. The production designer Alex McDowell, who was basically responsible for the look of the production, started his work with a tour through MIT's media lab, where he could see various demonstrations about gesture recognition projects or the kitchen of the future, getting an impression of the state of current research in this field. His aim was that the audience would be able to recognize the movie's future and relate to it. He wanted the society to be consumer-based, very market-driven, taking today's technological trends to their logical conclusion.

On his tour, Spielberg had the opportunity to talk to John Underkoffler, a gesture interface expert who was eventually hired as a consultant for this film, as well as Jaron Lanier, who claims to have coined the term Virtual Reality. Together with other consultants, a so-called 'Think Tank' was formed, where researchers brainstormed and developed their ideas about the future in 2048. The result of these efforts can be seen in various techniques appearing in the movie, which remind of ongoing or past projects at MIT or other institutes:

A typical tangible user interface (TUI) very similar to the Marble Answering Machine [15] by Gary Bishop at RCA London was used to represent offenders and victims to the system. Their names are engraved into wooden marbles, which then can be placed onto trays to obtain information. The Marble Answering Machine is a concept study of a common answering machine using marbles to represent incoming messages. Placing the marbles on different trays will for example play the message or dial the caller back.

The principle of a market-oriented future is primarily demonstrated by the immersive and personalized advertisements, which the main character encounters during the movie: In one scene he steps out of the subway and different commercials welcome him by his name and compete for his attention. Identification is done by a retinal scan at the subway's exit as described before. Another scene shows him entering a clothes shop and again he is recognized by a virtual shopping assistant who asks if he is pleased with what he bought before. His shopping behavior was stored and used to infer further recommendations (see fig.10).

This kind of personalized shopping guide certainly exists on certain websites $^{2}$ which use the concept of collaborative filtering. These sites make suggestions to buyers entering their website according to shopping behaviors of other customers who bought the same products. Identification in this case is very easy, since customers have to log in to process or-

\footnotetext{
${ }^{2}$ for example www.amazon.com
} 


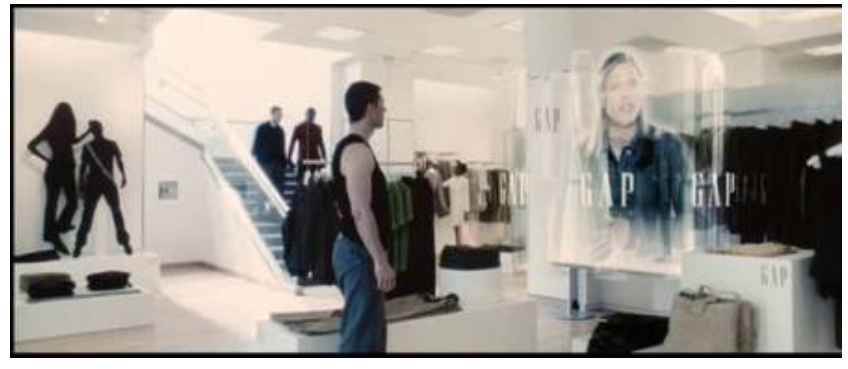

Figure 10: Personalized Shopping Assistance in Minority Report

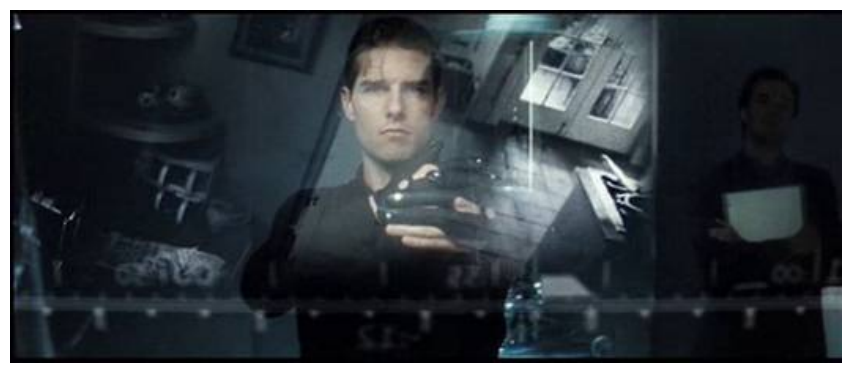

Figure 11: Gesture Interface in Minority Report

ders and also cookies can be stored for this task. In real life, identification is sometimes done via customer ID cards, which are processed when the client pays, but not (yet) when they enter the shop. Besides the field of online shopping, there also is considerable research to bring personalized and virtual shopping services into real shops, e.g. in [16] or [9].

The most apparent human-computer interface in MiNORITY REPORT $^{23}$ is the transparent screen with the gesture interface for browsing through the memories or visions of the so-called Pre-Cogs (see fig.11).

The user wears gloves with 3 reflective fingertips to achieve 6 DOF of hand movements, which is used for some carefully designed gesture metaphors to manipulate data and its layout on the screen. Besides the usual drag and drop functions, you can distinguish actions, such as cleaning the screen, which looks like a sweep with both hands emptying your desk, or the zoom function, activated by holding both hands in front of you with their palm side facing to you, the left hand representing the object such that you can zoom in by approaching it with the other hand. One scene also demonstrates the flaw that the system does not always recognize whether a user is trying to interact with it or doing something else with his or her hands: When someone else came in and wanted to shake hands, this movement accidentally caused an object on the screen to be misplaced.

The transparency of the big screen is not only useful for the high-tech look but it also enables the director to show the actor's facial expressions when operating the device, which is relevant for the plot of the movie. In one scene, personal data is literally carried from one screen to another on small glass tiles, in which one could recognize Jun Rekimoto's DataTiles [11]. The data is virtually connected to a

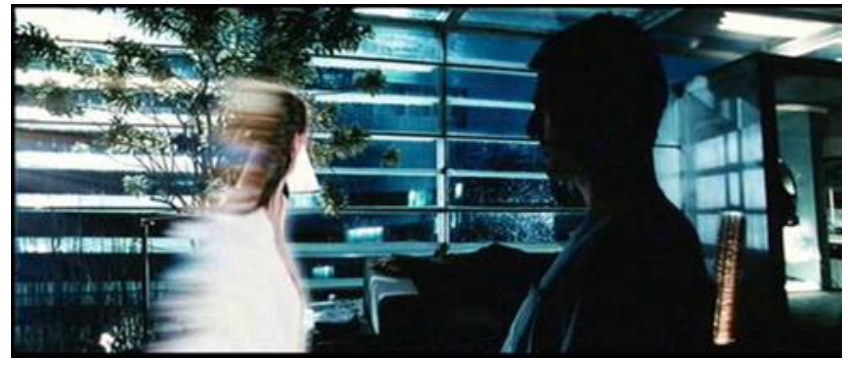

Figure 12: Distorted pseudo $3 \mathrm{D}$ projection in $\mathrm{Mi}-$ nority Report

data tile on one (small) screen and then physically taken to the main screen and connected there to use the data associated with it.

Another example of a technology which is currently under development is electronic ink. In MiNORITY REPORT ${ }^{23}$ it is shown once with a newspaper changing the displayed (animated and colored) articles and again when a box of corn flakes plays a multimedia clip on the box itself. The box is shaken several times, obviously in order to turn the animation off. A comparable product at present is the e-ink ${ }^{3}$ device, which was developed for e-book applications. This paper-like display is able to change its contents, but currently not yet quite as flexible.

A very popular biometric identification technology - as mentioned before - is the retinal and iris scan. Either the blood vessel patterns of the retina or the pattern of the iris can be used to uniquely identify individuals. The object doesn't necessarily have to interact with a device, since recognition currently works up to a certain distance (depending on the video system used), but alignment of the eye is still required [3]. Such systems are now gaining acceptance in many areas, and in an imaginative future as described in MiNORITY REPORT $^{23}$ they would be installed in public places, such as subway stations, which would enable the system's owner to track basically everybody and build a history of their activities. It is not required anymore that people would interact with a device, just passing by would suffice. First steps towards a large scale city-wide observation and recognition system aiming at 200.000 in- and outdoor cameras are now taken by the chinese government for the 10-millioncity Shenzhen, primarily for fighting crime and developing better controls on an increasingly mobile population ${ }^{4}$. Although the computer vision based recognition of individuals has a success rate of less than $60 \%$, we are now experiencing a development that not only this movie has indicated.

Holographic projections as discussed above are seen in MINORITY REPORT ${ }^{23}$ as well, where it is particularly interesting to see that distortions as a technological flaw have been included, which can be seen at the edge of the images, when the camera moves around the projection (see fig.12).

\footnotetext{
${ }^{3}$ http://www.eink.com/

${ }^{4}$ http://news.com.com/In+China\% $2 \mathrm{C}+\mathrm{a}+$ hightech+plan+to+track+people/2100-1028_3-6202080.html
} 


\section{ANECDOTES}

Some HCI movie scenes we found defy our classification in this work, but they are still worth to be presented here, because they reflect on interaction techniques in a satiric and entertaining way. Probably the most popular of these scenes can be found in Start TreK IV ${ }^{24}$ when McCoy and Scotty are on earth and supposed to use a 20th century personal computer. Scotty tried to talk to the PC in the same ways he was used to talk to the Enterprise's main computer, which of course failed. A 20th century human then politely hinted to use the mouse, which he did - assuming that it was a microphone. This scene nicely illustrates a clash in conceptual models between the GUIs of current personal computers and the perfect speech interface of the space ship.

The second scene is from GALAXY QUEST ${ }^{25}$, a science-fiction parody of STAR TREK ${ }^{17}$ in which a group of actors of a science-fiction series is abducted by an alien race, which had been watching the series from their planet, and now mistakes them for the real heroes. A copy of the (fictional) starship was built by the aliens and the 'crew' was forced to use it to help them, which was a difficult task for the actors, who had only pretended to control the space ship until then. Already their attempt to leave the space harbor miserably failed, severely damaging the space ship along the side walls. The entire movie is a very interesting twist on the interaction between science fiction films and reality.

The third ironic scene is a short part of an episode of the cartoon series FUTURAmA ${ }^{26}$. While the scene shows a group of people talking about a person called "Fry", the computer is listening and proactively assists by downloading a movie about this person, opening the owner's calendar on Friday and ordering some french fries. This accurately describes the current state of many search engines - be they web services or desktop applications - which often provide assistance based on keywords without knowledge of the context, and it satirically dismisses the very concept of proactive intelligent UIs.

\section{DISCUSSION}

As stated in the introduction, we discovered a certain pattern in the collaboration between filmmakers and scientists regarding the use of HCI in movies. After an initial phase of just unreflected citation of existing technology or simple extrapolation without conceptual changes, technology started to inspire filmmakers, they invented interesting variations or pointed out the consequences of failures (or total success for that matter) of technologies, and thereby provided inspiration for researchers all the same.

When researchers pick up ideas and concepts from Science Fiction movies, they often face major technological problems. It is very simple to mock up a new technology for the camera, but often very hard to really solve the underlying technical problems. Eventually, however, it can be observed, that researchers and filmmakers collaborate in order to create technologically feasible and believable, but still conceptually inspiring versions of the constructed future.

The collaboration patterns we observed don't always appear in a strict chronological order. Depending on the budget or imagination of the filmmakers, even the very first situation (i.e., unreflected citation) can occasionally still be found. In general, there is at least one important difference between a filmmaker's goals and those of an HCI researcher: While in the field of ubiquitous computing, it is a widespread ideal to create "calm technology", movies tend to present shiny and flashy "loud" interfaces, because of their visual appeal and effects.

Finally, movies have an impact on the consumer's mindset, which should not be underestimated: Popular shows, such as StAR TREK ${ }^{17}$ and Star WARs ${ }^{18}$ set the bar very high and have created an expectation for the average consumer which probably can't be met in the very near future (e.g., perfect speech interfaces, immaterial holographic display technologies). Researchers in turn respond to this by designing their interfaces in such a way, that they allude to popular movies: $\mathrm{STTNG}^{8}$, for example, uses a perfect speech interface to the main computer, and the Intelligent Room project at MIT[2] used the same sound design for their speech interface to the environment. Requests must be preceded by "Computer?" to which the computer will reply with a particular sound, signaling to the user, that the system is in a state to receive spoken commands. MinORITY REPORT's approach to design futuristic HCI counteracts this issue by deliberately incorporating technical flaws into their interfaces - another benefit of a cooperation between filmmakers and HCI scientists.

\section{ACKNOWLEDGEMENTS}

We would like to thank our readers, who commented a preliminary collection of these ideas on slashdot, boingboing etc. Our research was partially funded by the German Research Foundation (DFG).

\section{REFERENCES}

[1] B. Blankertz, G. Dornhege, M. Krauledat, K.-R. Mueller, V. Kunzmann, F. Losch, and G. Curio. The berlin brain-computer interface: EEG-based communication without subject training. IEEE Transactions on Neural Systems and Rehabilitation Engineering, 2006.

[2] R. Brooks. The intelligent room project. In Second International Conference on Cognitive Technology, 1997.

[3] J. Daugman and C. Downing. Epigenetic randomness, complexity and singularity of human iris patterns. In Proceedings of the Royal Society, B 268, Biological Sciences, page 1737-1740, 2001.

[4] R. Herrera and M. Tracey. Dna fingerprinting. basic techniques, problems and solutions. Journal of Criminal Justice, page 237-248, 1992.

[5] B. Johanson, A. Fox, and T. Winograd. The interactive workspaces project: Experiences with ubiquitous computing rooms. IEEE Pervasive Computing Special Issue on Overviews of Real-World Ubiquitous Computing Environments, April-June, 2002.

[6] A. Jones, I. McDowall, H. Yamada, M. Bolas, and P. Debevec. Rendering for an interactive $360^{\circ}$ light field display. In Proceedings of ACM SIGGRAPH 200\%. ACM press, 2007.

[7] M. Kruppa and A. Krüger. Concepts for a combined 
use of personal digital assistants and large remote displays. In Proceedings of Sim Vis 2003, page 349-361, 2003.

[8] M. Kruppa and A. Krueger. Performing physical object references with migrating virtual characters. In M. Maybury, O. Stock, and W. Wahlster, editors, Proceedings of the first conference on INtelligent TEchnologies for interactive enterTAINment (INTETAIN2005), pages 64-73, Madonna de Campiglio, Italy, 2005.

[9] E. Newcomb, T. Pashley, and J. Stasko. Mobile computing in the retail arena. In Proceedings of the ACM Conference on Human Factors in Computing Systems (CHI), pages 337-344, 2003.

[10] R. Raskar, G. Welch, and W.-C. Chen. Table-top spatially-augmented realty: bringing physical models tolife with projected imagery. In 2nd IEEE and ACM International Workshop on Augmented Reality (IWAR 'g9), 1999.

[11] J. Rekimoto, B. Ullmer, and H. Oba. Datatiles: a modular platform for mixed physical and graphical interactions. In CHI '01: Proceedings of the SIGCHI conference on Human factors in computing systems, pages 269-276, New York, NY, USA, 2001. ACM Press.

[12] C. Rocchi, O. Stock, M. Zancanaro, M. Kruppa, and A. Krueger. The museum visit: Generating seamless personalized presentations on multiple devices. In Proceedings of the International Conference on Intelligent User Interfaces IUI2004, Madeira, January, 2004.

[13] M. Schmitz, J. Baus, and S. Schmidt. Anthropomorphized objects: A novel interaction metaphor for instrumented spaces. In A. Q. Thomas Strang, Vinny Cahill, editor, Pervasive 2006 Workshop Proceedings. Deutsches Zentrum für Luftund Raumfahrt. ISBN 978-3-00-018411-6, 2006.

[14] M. Schmitz, A. Krüger, and S. Schmidt. Modelling personality in voices of talking products through prosodic parameters. In Proceedings of the 10th International Conference on Intelligent User Interfaces, pages 313-316, 2007.

[15] G. C. Smith. The marble answering machine. In The Hand That Rocks the Cradle, pages 60-65, May/June 1995.

[16] C. Stahl, J. Baus, B. Brandherm, M. Schmitz, and T. Schwartz. Navigational- and Shopping Assistance on the Basis of User Interactions in Intelligent Environments. In Proceedings of the IEE International Workshop on Intelligent Environments (IE 2005), University of Essex, Colchester, UK, 2005.

[17] P. Tandler, T. Prante, C. Müller-Tomfelde, N. Streitz, and R. Steinmetz. Connectables: dynamic coupling of displays for the flexible creation of shared workspaces. In UIST '01: Proceedings of the 14th annual ACM symposium on User interface software and technology, pages 11-20, New York, NY, USA, 2001. ACM Press.

[18] R. Want, B. Schilit, N. Adams, R. Gold, K. Petersen, D. Goldberg, J. Ellis, and M. Weiser. The PARCTAB ubiquitous computing experiment. Technical Report CSL-95-1, Xerox Palo Alto Research Center, Mar. 1995.

\section{MOVIE REFERENCES}

1. Star WARs: EPISOde II (2002, USA), directed by George Lucas

2. Le VOyage DANS LA Lune (1902, France), directed by Georges Méliès

3. Metropolis (1927, Germany), directed by Fritz Lang

4. Raumpatrouille Orion (1966, West Germany), directed by Rolf Honold

5. Battlestar Galactica (1978, USA), created by Glen A. Larson

6. Password Swordfish (2001, USA), directed by D. Sena

7. Johnny Mnemonic (1995, USA/Canada), directed by Robert Longo

8. Star Trek: The Next Generation (1987, USA), created by Gene Roddenberry

9. Colossus: The Forbin Project (1970, USA), directed by Joseph Sargent

10. The Bourne Identity (2002, USA/Germany), directed by Doug Liman

11. The Matrix (1999, USA), directed by the Wachowski Brothers

12. LogAN's Run (1976, USA), directed by Michael Anderson

13. Gattaca (1997, USA), directed by Andrew Niccol

14. Alien 4 (1997, USA), Jean-Perre Jeunet

15. X-Men (2002, USA), directed by Brian Singer

16. Forbidden Planet (1956, USA), directed by Fred M. Wilcox

17. Star TreK: Enterprise (2001, USA), created by Rick Berman

18. StAR WARS (1977, USA), directed by George Lucas

19. Total Recall (1990, USA), directed by Paul Verhoeven

20. 2001 - A Space Odyssey (1978, USA), directed by Stanley Kubrick

21. DARK StAR (1974, USA), directed by John Carpenter

22. Time Machine (2002, USA), directed by Simon Wells

23. Minority Report (2002, USA), directed by Steven Spielberg

24. Star Trek IV: The Voyage Home (1986, USA), directed by Leonard Nimoy

25. Galaxy Quest (1999, USA), directed by Dean Parisot

26. Futurama (1999 - 2003, USA), by Matt Groening 